Agamben is right: COVID 19 and permanent state of exception

\title{
Agamben tiene razón: COVID 19 y estado de excepción permanente
}

Guillermo Andrés Duque Silva

Universidad Rey Juan Carlos

fielalatierra@hotmail.com

Cristina Del Prado Higuera

Universidad Rey Juan Carlos

cristina.delprado@urjc.es

DOI: https://doi.org/10.15366/bp2021.27.005

Bajo Palabra. II Época. No 27. Pgs: 105-124

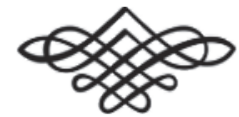


Recibido: 18/12/2020

Aprobado: 07/05/2021

\section{Resumen}

El COVID 19 además de haber enfrentado al mundo a una crisis sanitaria sin precedente, ha servido para que algunos filósofos entre ellos Giorgio Agamben hayan abordado esta crisis desde una perspectiva política y social, analizando el permanente estado de excepción en el que estamos viviendo. En este artículo intentamos mostrar la visión de cómo las situaciones extremas se convierten en paradigmas de lo cotidiano si no somos capaces de analizarlas de una manera correcta.

Palabras clave: Estado de excepción, teología política, COVID-19, soberanía.

\section{Abstract}

COVID 19, in addition to confronting the world with an unprecedented health crisis, has helped some philosophers including Giorgio Agamben address this crisis from a political and social perspective, analyzing the permanent state of emergency in which we are living. In this article, we try to show the vision of how extreme situations become paradigms of the everyday if we are not able to analyze them in the right way.
Keywords: State of exception, political theology, COVID-19, sovereignty. 


\section{Introducción}

A InICIOS DEL AÑo 2020 tuvo lugar un importante debate filosófico por cuenta de la crisis del COVID 19. Diversos pensadores contemporáneos como Slavoj Žižek, Roberto Esposito y Jean-Luc Nancy plantaron sus posiciones respecto a la situación crítica que se estaba gestando. En febrero de 2020, el filósofo italiano Giorgio Agamben irrumpió con una nota de prensa que despertó las más implacables críticas desde la comunidad filosófica. El título de la publicación: La invención de una epidemia ${ }^{I}$ dejó ver la postura crítica que Agamben esgrimía contra las medidas que se han impuesto desde los Estados para enfrentar la emergencia sanitaria. En esa publicación, el reputado filósofo calificó las respuestas estatales a la crisis pandémica de "frenéticas, irracionales y completamente injustificadas" 2 . Agamben cuestionó porqué los medios de comunicación y las autoridades se esforzaban "por difundir un clima de pánico, provocando un verdadero estado de excepción, con graves limitaciones de los movimientos y una suspensión del funcionamiento normal de las condiciones de vida y de trabajo en regiones enteras" ${ }^{3}$. Desde la perspectiva de Agamben, esas medidas eran totalmente desproporcionadas frente a lo que, según él, era una gripe normal.

La oleada de críticas contra Agamben no se hizo esperar; las más importantes las reconstruiremos en el artículo. No vamos a discutir aquí la capacidad destructiva del virus, toda vez que la calificación del COVID 19 que hace Agamben como una simple gripe, se cae por sí sola ${ }^{4}$. Lo que nos interesa es la relación que establece Agamben entre la emergencia del COVID 19 y su conceptualización de un estado de excepción permanente.

Agamben se ha dedicado, por más de veinte años al estudio erudito del estado de excepción en la cultura occidental, lo que en su propuesta pertenecía a un plano teórico y abstracto de repente, adquiere corporeidad frente a él en la respuesta globalmente extendida al COVID 19. Por ello, más allá de la polémica posición de Agamben sobre la letalidad del virus, nos interesa la apreciación que el filósofo

\footnotetext{
Agamben, G. "La invención de una epidemia", Sopa de Wuhan, Argentina, ASPO, 2020, pp. 17-20.

2 Ibid., p. 17.

3 Ibid., p. 18.

${ }^{4}$ El mismo Agamben, el 28 de marzo afirmaba que, por un lado, se había basado en las cifras que el Consejo Nacional de Investigación italiano de una etapa temprana de la epidemia y que, por otro lado, él no era virólogo, ni médico.
} 
realiza acerca de una tendencia creciente a utilizar el estado de excepción como paradigma normal de gobierno, propensión en la cual el COVID 19 se posiciona como su más reciente capítulo5.

En este artículo cumpliremos con tres propósitos, en tres secciones. Primero, abordaremos la propuesta teórica del estado de excepción de Giorgio Agamben en diálogo, por un lado, con las críticas recibidas de otros filósofos, y por otro lado en relación con las posibles aplicaciones que dicha teoría tendría en situaciones concretas generadas por la crisis del COVID 19. En segundo lugar, analizaremos el marco conceptual de la teología política y la teología económica en Giorgio Agamben, especialmente la desarrollada en El Reino y la Gloria, para ponerla en contexto frente a la crisis sanitaria y la pregunta por el origen y legitimidad de las leyes y medidas que afectan la vida social en el estado de excepción generado por el coronavirus. En la tercera y última sección, llamaremos la atención sobre el alcance del actual estado de excepción que, en el marco teórico agambeniano, no se superará con el final de la pandemia, del mismo modo en que no inició con ella.

\section{El Estado de excepción agambeniano: la soberana decisión del respirador.}

El ITALIANO ES CONSIDERADO EL PRINCIPAL HEREDERO del método genealogista de la política de Michel Foucault. Agamben describe la edad contemporánea como una época que logra cristalizar el diagnóstico que Foucault dejó entrever alrededor del concepto de "biopolítica", en sus últimas obras. La noción de biopolítica ha sido empleada para describir la administración del poder en la vida humana como paradigma de gobierno en la cultura occidental. Según la concepción que Foucault tenía de los poderes humanos; éstos actúan en dos sentidos ${ }^{6}:$ impulsan la vida o acaban con ella ${ }^{7}$. Desde la primera perspectiva, la del impulso de la vida, los seres humanos son estrictamente la materia prima por preservar para los agentes de poder, sin embargo, en la segunda, los agentes de poder se ven compelidos a ejercitar mecanismos que terminan con la vida de una parte de la población que administran. Las dos visiones son complementarias, pues finalmente, gracias a la muerte de unos sujetos, se intenta proteger la vida de otros. Giorgio Agamben, rescata ese concepto de la biopolítica para describir la sociedad contemporánea y da

\footnotetext{
5 Ibid., p. 18.

${ }^{6}$ Foucault, M. "Il faut défendre la société", Cours au Collège de France (1975-1976), Paris, Gallimard-Seuil. 1997, p. 218.

7 Duque Silva, G. A. "El Carl Schmitt de los tanato-políticos: la veta de filosofía schmittiana en el pensamiento de Giorgio Agamben”. Praxis flosófica, (45), 2017, p. 109.
} 
un paso más: enfoca su atención en una perspectiva pesimista de la biopolítica, se dedica a comprender los criterios de administración de la muerte que se ejercen en la historia de Occidente para identificar patrones biopolíticos en los gobiernos de las sociedades occidentales, así como las posibilidades, reducidas, de resistencia que pueden emerger en un mundo que se ido convirtiendo, según el filósofo italiano, en un "gigantesco campo de concentración".

Desde la perspectiva de Agamben, las crueldades más reprobables que han tenido lugar en el ejercicio del poder en Occidente, en lugar de ser anomalías excepcionales, constituyen paradigmas inherentes al proceso de construcción social de la modernidad $^{9}$. A su manera, Giorgio Agamben interpreta la sentencia de Ernst Nolte, quien afirmaba que, con Auschwitz, la historia se resistía a quedar en el pasado. En efecto, Auschwitz constituye el paradigma obsceno de lo moderno que Agamben convierte en el mito fundacional de una era biopolítica; un paradigma que se resiste a "quedar en el pasado" y que dota de sentido las formas contemporáneas de gobierno. El italiano sigue el débil, pero constante latido del musselman ${ }^{10}$ de Auschwitz; y le persigue desde el presente hasta sus más remotos orígenes. El filósofo realiza, en un programa de investigación de una década y seis libros, una prodigiosa arqueología del poder para hallar entre sus significados, el núcleo esencial de lo moderno, una explicación a la pregunta: ¿cómo pudimos llegar a Auschwitz?: en esa genealogía halla los orígenes del concepto de nuda vida. ${ }^{11}$

La vida contemporánea, en la biopolítica explicada por Agamben, se ha tornado en una nuda vida. La vida así concebida se reduce a lo producido y lo gestionado por el derecho. A los individuos de un campo de concentración, se les despoja de todo derecho y condición político-jurídica, su vida es tratada, desde los agentes de poder, como materia sin forma humana, vida desnuda: son datos, cifras, unidades biológicas siempre sacrificables ante el valor prioritario del futuro y la conservación, paradójicamente, de otras vidas ${ }^{12}$. Ante el Gobierno que ejercen los agentes de poder, la nuda vida, según Agamben, da lugar a una pauperización de la vida humana. Entre los sujetos del campo de concentración, Agamben se centra en dos figuras, el musselman, por una parte, representa la figura más extrema en el campo de concentración; resignado a morir, está envuelto en la humillación, el miedo y el

\footnotetext{
${ }^{8}$ Agamben, G. Lo que queda de Auschwitz. El archivo y el testigo. Homo sacer III, Valencia, Pre-Textos, 2000, p.50.

9 Agamben, G. Profanaciones, Barcelona, Editorial Anagrama.

${ }^{10}$ El término se usaba en los campos de concentración para referirse de forma despectiva a los prisioneros que caían de rodillas con la cabeza en el suelo por hambre y agotamiento, eran los "resignados a morir", quienes no representaban, para los agentes de poder, ningún valor biopolítico.

${ }^{11}$ Las obras en las que desarrolla el este concepto son Homo Sacer: El poder soberano y la nuda vida, Lo que queda de Auschwitz: el archivo y el testigo y Estado de Excepción. Homo Sacer II, 1.

12 Agamben, G. Medios sin fin. Notas sobre la politica,Valencia, Pre-Textos, 2001, pp. 37-43.
} 
horror. Por otra parte, se encuentra el homo sacer, quien vive atrapado en medio de una estrecha incongruencia, por un lado, lleva la carga de un delito, pero es jurídicamente insacrificable, es decir está prohibido someterle a muerte al mismo tiempo que tiene que vivir sabiendo que a los demás les está permitida la impunidad si le dan muerte ${ }^{13}$. Agamben avanza y relaciona la nuda vida y el homo sacer como metáforas de la vida moderna y al campo de concentración como su paradigma.

"La nuda vida [como vida para la muerte] no es la simple vida natural, sino una vida políticamente desprotegida, permanentemente expuesta a la muerte o a las vejaciones ocasionadas, con impunidad total, por el poder soberano o por quienes lo componen como ciudadanos" ${ }^{14}$.

Es inevitable comparar el concepto de nuda vida de Agamben con sus afirmaciones sobre la enfermedad y los estados de emergencia que ha generado el COVID 19. Particularmente, llaman la atención las diferencias intergeneracionales que se promueven en defensa del bienestar general. Todos, pero particularmente las generaciones más adultas han experimentado, de cierta manera, el estar encerrados en una vida políticamente desprotegida; permanentemente expuesta a la muerte. El anciano se ha convertido en un musselman del siglo XXI, un ser resignado a morir que es a la vez insacrificable, en la medida en que su muerte no es ordenada directamente, sino que se espera como un resultado natural del aislamiento que ofrecen, en España, por ejemplo; las residencias de mayores. Su muerte es considerada como un resultado natural e inevitable. El que la elección entre salvar a una persona joven o a un anciano proporcionando un respirador a quien "tiene toda una vida por delante", en ningún momento admita la opción de considerarse como un acto criminal, nos pone frente a frente con el biopoder; si el sentido de esa elección tiende a naturalizarse, es porque en esa normalización del horror radica la esencia de la administración del poder en la edad contemporánea, un poder que, literalmente, impulsa una vida y acaba con otra.

Este es el sentido de la descarnada crítica que realiza Agamben al trasfondo político de la emergencia sanitaria, el cual, no solo afecta a los ancianos como musselman del siglo XXI, sino que, en general, se dirige a todos los individuos de la civilización occidental; destinados a convertirse en homo sacer contemporáneos. Para Agamben el mensaje que sustenta la biopolítica del COVID 19 se basa en la

\footnotetext{
${ }_{13}$ Agamben, G. Homo sacer. I. El poder soberano y la nuda vida, Valencia, Pre-Textos, 1998, p. 94.La cita directa de Agamben proviene del tratado Sobre la significación de las palabras de Festo: "el homo sacer, es aquel a quien el pueblo ha juzgado por un delito; no es lícito sacrificarle, pero quien le mate, no será condenado por homicidio.

${ }_{14}$ Agamben, G. Citado por: Múnera, L., \& Benavides, F. Normalidad y excepcionalidad en la politica (Schmitt, Agamben, Žižek y Virno), Colección Gerardo Molina, (Vol. 13), Bogotá, Universidad Nacional de Colombia, 2008, p. 13.
} 
promoción del horror: la máquina gubernativa nos declara que: "nuestro prójimo ha sido abolido" ${ }^{15}$, el enemigo es aquel que puede contagiarme, nuestros vecinos son una potencial amenaza a la que debemos temer. En resumen, lo que Agamben indica es que, creemos actuar en libertad aun con las restricciones que imponen los Estados en respuesta al COVID 19, cuando "en realidad vivimos en una sociedad que ha sacrificado la libertad por unos supuestos 'motivos de seguridad' y se ha condenado, por ello, a vivir en un estado permanente de miedo y de inseguridad" 16 .

La soberanía que ejercen los poderes gubernativos en esta interpretación de Agamben no requiere mayor legitimidad que el mismo hecho de disponer de la vida de los súbditos, es decir, son decisiones justificadas en los agentes de gobierno "por el simple hecho de su soberanía" ${ }^{17}$. Es esto lo que fundamenta como legal y legítima la decisión soberana del respirador, que más allá de ser real, de haberse presentado o no, opera como síntoma de una soberanía que no necesita razones para ejercerse ${ }^{18}$.

Para Agamben, la forma como esta soberanía se gesta guarda una estrecha relación con la dualidad entre normalidad y excepción que planteó Carl Schmitt, sin embargo, rompe el esquema dicotómico que caracterizó al jurista de Plettenberg. Agamben indica que soberano no es quien decide en y sobre el estado de excepción, sino que lo conforma quien es capaz de mantener las acciones excepcionales como un ámbito sujeto a su control y presentarlas como acciones normales. Así, a la vieja lógica: normalidad - excepción - nueva normalidad que ansiaríamos con el esquema de Schmitt; Agamben opone una noción de excepcionalidad permanente. Si Carl Schmitt llegó a afirmar que "el soberano está al mismo tiempo, fuera y dentro del ordenamiento jurídico" ${ }^{19}$ por su capacidad de suspender la normalidad con la declaración del estado de excepción; para reinstituir un orden jurídico nuevo, Giorgio Agamben da un paso más y afirma que su soberano actúa bajo un imperativo autojustificativo, que indica: "la ley está fuera de sí misma y Yo, el soberano, que estoy por fuera de la ley, declaro que no hay un afuera de la ley" ${ }^{20}$.

\footnotetext{
15 Agamben, "Contagio", Sopa de Wuhan, Argentina, ASPO, 2020, pp. 31-33.

16 Agamben, G. "Aclaraciones”. La fiebre. Pensamiento contemporáneo en tiempos de pandemias. Argentina, ASPO, 2020 , p. 255.

${ }_{17}$ Múnera, L., \& Benavides, F. op. cit., p. 15.

${ }_{18}$ Agamben ha demostrado en su genealogía del gobierno que este tipo de decisiones han estado presentes en todo el proceso de constitución de la modernidad. Son decisiones auto justificadas presentes en la creación de las instituciones disciplinarias y sanitarias, están también en la bases de la administración de los sistemas pensionales $y$, recientemente, en la lucha contra los enemigos gaseosos e indeterminados de Occidente que se encierran en la palabra: terrorismo. La diferencia de la emergencia del COVID 19 consiste en que nos ha permitido experimentar este tipo de decisiones de primera mano, ya que cualquiera puede ocupar el lugar proscrito del homo sacer, es decir, del ser enfermo.

19 Schmitt, C. Teología politica, Madrid, Trotta, 2009, pp. 13-20.

${ }^{20}$ Agamben, G. Homo sacer. I. El poder soberano y la nuda vida, Valencia, Pre-Textos, 1998, p. 27.
} 
Mientras que en el planteamiento schmittiano, la excepcionalidad y la soberanía son atributos propios de la lucha política ${ }^{21}$; en Agamben el lugar del poder y su ejercicio; son trascendentes a los grupos y actores políticos en cuanto tal, en la medida en que se expresan desde una excepcionalidad permanente que, no obstante, fundamenta la aplicación de la ley. Entonces, mientras que el soberano para Schmitt puede ser un partido político, un monarca, un líder populista o, inclusive, en su última etapa, un grupo guerrillero que toma la decisión en y sobre el estado de excepción, para Agamben ese papel no lo desempeña un gobierno, sino el acto mismo de gobernar ${ }^{22}$. Es decir, no es resultado de un decisor específico, sino del ordenamiento social y legal que se ha construido en Occidente ${ }^{23}$, una forma de excepcionalidad que se expresa de forma permanente, sin descansos o pretensiones de nuevas normalidades. Para Agamben, la soberanía y el derecho que de ella emana, no surgen de las pausas de excepcionalidad que plantea Schmitt, pues en el Occidente contemporáneo, ya no hay nada más normal que vivir en un permanente estado de excepción. En otras palabras, el estado de excepción en el pensamiento de Giorgio Agamben no se caracteriza por su anormalidad y contingencia, no se explica en función de la "normalidad por venir", sino por su permanencia, por ello es, en la mayor de las ocasiones, una excepcionalidad imperceptible ${ }^{24}$.

Aunque el planteamiento de un estado de excepción permanente ubica a la crisis del COVID 19, en un panorama amplio, las críticas recibidas por otro investigador de la biopolítica, Roberto Esposito, reflejan que aún es pronto para ver más allá de la "cifras de muertos", como insta Agamben. Todavía no es momento de analizar el efecto cualitativo que dejará a largo plazo la decisión de poner a la humanidad y sus libertades en cuarentena. Concretamente, Esposito indica a Agamben que la comparación entre pasar unos días de aislamiento en una cómoda casa de clase media italiana y el horror de un campo de concentración es inverosímil e irresponsable ${ }^{25}$. Tiene razón Esposito, sin embargo, deberíamos agregar a su réplica que tampoco es igual la forma como se asumen las restricciones del COVID 19 en regiones del mundo en las que, por ejemplo, lavarse las manos con agua y jabón ha sido, durante siglos, un lujo. Entonces, lo que parece perder de vista Esposito, es que lo excepcional no lo dictan las circunstancias en que se asume, por ejemplo, un aislamiento, sino que deviene de la forma en que internalizamos como

\footnotetext{
${ }^{21}$ Duque Silva, G. A., \& Del Prado, C. "A 100 años de la Constitución de Weimar ¿qué nos queda?: La herencia polémica de Carl Schmitt”. Bajo Palabra. Revista de Filosofía. II Época, Madrid, UAM, 2020, p. 286.

22 Agamben, G. Estado de excepción. Homo Sacer II, 1, Buenos Aires, Adriana Hidalgo, 2004, p. 75.

23 Ibid., p. 34.

24 Ibid., pp. 75-100.

25 Esposito, R. “Curati a oltranza”. Antinomie, 2020.Disponible en: https://antinomie.it/index.php/2020/02/28/ curati-a-oltranza/
} 
normal lo que no debe ser, bajo ningún punto de vista, aceptado ${ }^{26}$. Luego, hemos internalizado como algo "normal", por ejemplo, el que vastas regiones del mundo vivan sometidas a la cuarentena que impone el hambre y la miseria. Agamben nos recuerda que la verdadera plaga no es otra que la mansedumbre con que se acepta convivir con situaciones excepcionales y reprobables ${ }^{27}$. Finalmente, en eso consiste el ejercicio de la soberanía en la era biopolítica, en un estado de excepción que no nació con el COVID-19 28 .

\section{Teología política y COVID 19: el pueblo reina, pero no gobierna.}

Muchas de las críticas que recibió Agamben lo ubicaron en las posiciones conspi-paranóicas que adjudican a los Estados y a las élites capitalistas la responsabilidad de propagar el terror en las ciudadanías cuando, de hecho, ha sido el capitalismo y sus élites de gobierno los principales afectados con la crisis. La crítica de Žižek a Agamben, por ejemplo, puso en cuestión el beneficio que puede traer el estado de emergencia a los gobiernos y a las élites capitalistas pues, al final de cuentas, la emergencia ha acentuado, por un lado, una desconfianza generalizada en el papel del Estado y, por otra parte, una crisis económica sin precedentes. Žižek le pregunta a Agamben: ¿qué elite estaría interesada en promover semejante movimiento en contra de sus propios intereses? ${ }^{29}$. La respuesta a favor de Agamben frente a esta interrogante, la podríamos encontrar en la crítica que, a su vez, Paolo Flores d'Arcais, en su revista MicroMega, realizó al propio Agamben. Para Flores d'Arcais el COVID 19, no ha afianzado el poder del Estado ni del capital, en eso coincide con Žižek, sino que se ha caracterizado por la aparición de una nueva "conspiración de batas blancas": médicos y científicos que figuran hoy como depositarios de la "última palabra" en el gobierno sobre la vida; por encima, según Flores d'Arcais, de los intereses de los gobiernos y el capital ${ }^{30}$.

Si ponemos el foco en la forma como se toman las decisiones en el estado de excepción del COVID-19, y en el marco teórico agambeniano, veremos que los gobiernos se apoyan en el argumento médico-científico para justificar sus decisiones

\footnotetext{
${ }^{26}$ Agamben, G. ¿En qué punto estamos? La epidemia como política (T. D’Meza \& R. Molina-Zavalía, Trads.). Buenos Aires, Adriana Hidalgo, 2020, pp. 31-37.

27 Agamben, G. "Reflexiones sobre la peste" Sopa de Wuhan, Argentina, ASPO, 2020, pp. 135-137.

${ }^{28}$ Un indicador del poder de internalización del estado de excepción puede ser la manera como hemos normalizado el uso de la mascarilla, en muchos casos ha pasado de ser de incómoda a imperceptible; el rostro desnudo del otro, casi escandaloso, ha pasado ser lo extraño.

29 Žižek, S. Pandemia. La COVID-19 estremece al mundo, Barcelona, Anagrama, 2020, p. 79.

${ }^{30}$ Flores D’Arcais, P. “Filosofia e virus: Le farneticazioni di Giorgio Agamben”, MicroMega, 2020, Disponible en: http://temi.repubblica.it/micromega-online/filosofia-e-virus-le-farneticazioni-di-giorgio-agamben/
} 
con dos beneficios; por un lado, eluden la necesidad de someter sus planteamientos a la exigente deliberación de los sistemas democráticos y, por otro lado, les exime de responsabilidades de origen; como simples operadores de una decisión científica que, al fin de cuentas, les es ajena. Entonces, aquella última decisión de las "batas blancas" a la que se refiere Flores d'Arcais, no se toma por encima de los gobiernos, sino que es utilizada por estos últimos como un argumento de autoridad que opera de forma teológica. Es decir, si consideramos el trasfondo teológico en que surgen las decisiones científicas que, posteriormente, sustentan las acciones de gobierno, vemos una correlación entre las autoridades terrenales de gobierno y la "soberanía científica", que auto justifica las decisiones coercitivas bajo el halo irrefutable que ofrece la medicina. En el largo plazo, contrario a lo que dice Žižek, esas medidas que en principio parecen afectar al capital y a los Estados les fortalecerán notablemente, pues habrán vuelto normal lo excepcional, de forma acelerada y con un alto coste democrático que será difícil de recuperar. Al final, con el argumento irrefutable y autoimpuesto de la "razón medica", los gobiernos que han sustentado la suspensión temporal del orden jurídico habrán podido justificar un control nunca visto sobre el individuo y la sociedad; para protegerlos de un peligro igualmente inédito. En resumen, a fuerza de la dualidad medicina-política se forja, en la crisis del COVID 19, una versión contemporánea de la dualidad teología-política que estudió Agamben, para explicar que quién realmente gobierna es aquel poder capaz de convertir el estado de excepción en regla, y el mundo; en un gigantesco "campo de concentración". Vista así, la relación entre teología y política que se puede establecer en las decisiones para contener el COVID 19, viniendo de Agamben, no corresponde, de ningún modo, con una apreciación conspi-paranóica.

En la propuesta académica de Agamben, el mundo configurado como un campo de concentración es anterior al COVID 19; de hecho, es tan antigua como la formación misma de las sociedades occidentales. ¿Cómo explica Agamben que llegáramos hasta este punto? Agamben considera que la historia de Occidente es la historia de la creación de una "máquina gubernativa" biopolítica bipolar, que opera de forma teológica sobre las vidas humanas, a pesar de haber eliminado la necesidad de sustentar sus acciones en alguna esencia o sustancia política básica, es decir: una maquinaria de gobierno que no necesita remitirse a un cimiento divino $y$, sin embargo, se presenta, siempre, como una institución sagrada.

El gobierno biopolítico se reviste con la majestuosidad de lo celestial sin tener, propiamente, una sustancia divina de la cual emana su autoridad. En el Reino y la Gloria Agamben realiza un ejercicio genealógico del gobierno moderno, en el que explica el surgimiento de dicha máquina gubernativa, trasladándose a los orígenes teológicos judeocristianos. Ese desarrollo genealógico es altamente pertinente para 
entender la crítica realizada por Agamben al estado de excepción global que ha desatado el COVID 19.

La investigación de Agamben permite comprender que la cultura moderna occidental ha construido un tipo de gobierno que puede prescindir de la necesidad de remitir sus decisiones a un poder fundamental, esencial y superior y, aun así, operar bajo principios teológicos. Lo moderno entendido así, no supone, ni tanto menos surge, de la ruptura entre sustancia y forma, ni de la separación entre auctoritas y potestas; sino del descubrimiento de un poder divino ausente, inmóvil, cuya sacralidad depende, no de sí mismo, sino de la glorificación de quienes, sin ser Dios, han asumido la gestión de su praxis en la tierra. En el gobierno moderno, el nivel providencial y el científico, el del poder y el de la autoridad componen dos polos que cooperan entre sí: mantienen el lugar de lo sagrado como un trono vacío, es decir sin una sustancia específica y, al mismo tiempo, conservan la sacralidad en los ritos de la gestión que, "en nombre de lo sagrado", realizan los ángeles, ministros, pastores, los santos para cada plegaria y, en general; todos los responsables burocráticos de la praxis divina.

Para llegar a esa conclusión Agamben afronta la tarea de realizar una genealogía del gobierno, similar a la que realiza Foucault y, ciertamente, le supera. Mientras que el filósofo francés encuentra en la labor pastoral del cristianismo en sus primeros dos siglos, el momento auténticamente moderno que funda el nacimiento del poder político en la contaminación teológica del mundo del gobierno humano ${ }^{31}$, Agamben analiza, en variados tratados teológicos, cómo lo político está, además, presente en los orígenes de los discursos dogmáticos religiosos judíos y cristianos. Agamben explica, por ejemplo, que el término oikonomía, que caracteriza la primera gestión privada de los pater de familia, no solo tiene las implicaciones políticas que conocemos hoy en los Estados, sino que tuvo y tiene profundas implicaciones teológicas a las que Foucault no dedicó suficiente atención. Así la administración doméstica a la que remite la oikonomía moderna hace parte tanto de lo teológico como de lo político ${ }^{32}$. Por ejemplo, la Santísima Trinidad expresa una forma de gestión política del mundo, la economía se aplica en ella como una articulación interna que favorece su praxis, es gracias a ella que las tres personas que le componen son unidad y a la vez pluralidad de acciones; aquí la economía no solo actúa

\footnotetext{
31 Recordemos que para Foucault dicho momento se caracteriza por transformar el poder en un atributo de gestión propiamente humano, es decir, desligado de la soberanía trascendental; el poder político moderno, es decir la capacidad de proveer seguridad, administración y gestión al Estado, nacería, en la perspectiva de Foucault, de ese poder pastoral, en esencia privado y orientado a la técnica económica que los sacerdotes y primeros líderes cristianos realizaban sobre su rebaño y sobre cada una sus "ovejas".

32 Agamben, G. El reino y la gloria. Traducción: Flavia Costa y Edgardo Castro, Buenos Aires, Editorial Adriana Hidalgo, 2008, p. 76.
} 
de forma equivalente, como una metáfora, de la moderna separación de los poderes legislativo, ejecutivo y judicial - como indicó Foucault - sino que constituyen su origen histórico, pues tuvo lugar primero en la teología y después en la política ${ }^{33}$. En síntesis, a través de un análisis a tratados teológicos, que son en sí mismos un hallazgo invaluable, Agamben supera, por un lado, el nexo causal entre teología y política y, por otro lado, cuestiona la sobrevalorada secularización de los conceptos teológicos presentes, por ejemplo, en Carl Schmitt. Para Agamben toda teología está en la base de la política, de la misma manera en que la política lo estuvo en la base de la teología judeocristiana. El asunto problemático ha sido que el aparato burocrático de "administradores domésticos", aquellos que hoy dictan las órdenes de restricción de movimiento, por ejemplo, ha evolucionado hasta llegar a las actuales formas de dominio absoluto sobre la vida social, sin que el fundamento de esas medidas provenga de un poder igualmente absoluto.

Aunque Agamben se remita a antiguos textos teológicos, no tiene otra cosa en mente más que la actual decadencia política, la tendencia al autoritarismo y la crisis de las democracias liberales. Considera que la actualidad se caracteriza por el triunfo totalizador del gobierno económico de la vida en todas sus dimensiones. Con su genealogía Agamben demuestra que la cosificación de la vida como un bien administrable no ha sido, siempre, el paradigma imperante. Por el contrario, Agamben explica que el nacimiento de la perspectiva moderna frente al poder se ubica, precisamente, en la separación entre dos paradigmas y en la posterior toma de autonomía de uno sobre el otro: una teología política y una teología económica. En la primera, la voluntad de Dios es el origen del poder soberano; es en ella donde reside el plan divino de salvación en la cultura judeocristiana. En la segunda, tanto la vida de Dios como la humana son materia gestionable, son objetos de una economía de la vida administrada por expertos y autoridades autorizadas para resolver las vicisitudes humanas ${ }^{34}$. la teología política, funda en Dios la trascendencia del poder soberano, y la teología económica sustituye dicha trascendencia por la idea de una oikonomia concebida como orden inmanente ${ }^{35}$. La crisis política contemporánea, aquella que ha conducido a crear este gigantesco campo de concentración, exacerbado por el COVID 19, se basaría en que la teología política ha perdido casi todo terreno frente a la teología económica, un ámbito del poder que adquiere independencia y que no necesita justificarse en la voluntad de Dios, es decir, en un poder

\footnotetext{
${ }^{33}$ El dispositivo estratégico fundamental que imprime a la oikonomia un nuevo sentido, presente en la política moderna, es la inversión del sintagma paulino "economía del misterio" en "misterio de la economía" Ver: Agamben, G. El reino y la gloria, op. cit., p. 76.

${ }^{34}$ Agamben, G. El reino y la gloria, op. cit., p. 17, 58.

35 Galindo Hervás, A. "La gloria y el concepto de lo político en Giorgio Agamben", Revista de Estudios Sociales, (35),66-77, Colombia, Universidad de Los Andes, 2010, p. 68.
} 
auténtico y trascendente, para gobernar. En esa fractura entre Dios y su praxis es que Agamben identifica el surgimiento de la "máquina gubernativa de Occidente", una máquina bipolar que separa la omnipotencia de Dios, del gobierno racional del mundo, es decir, el poder absoluto, de su ejercicio mundano.

Para explicar mejor esto, Agamben analiza el lema de las monarquías constitucionales con el que se diferencia Reino y Gobierno, así describe de forma gráfica su hallazgo sobre la fractura de Dios: del mismo modo en que "el rey reina, pero no gobierna", Dios reina, pero no gobierna en las sociedades modernas de tradición judeocristiana. La teología económica cobra mayor independencia a medida que se abroga el terreno del gobierno sustentando su exclusividad sobre todo "aquello que Dios no puede hacer", ese terreno entre los desafíos del día a día humano y el misterio de la verdad divina, "se convierte en el paradigma de la distinción entre el poder y su ejercicio, entre Reino y Gobierno" 36 .

Esta escisión nos presenta a un Dios impotente ante su creación, pues "no puede actuar más que a través del orden natural que él mismo ha establecido" ${ }^{37}$, es decir, puede hacerlo todo, pero no puede hacer nada que no sea una respuesta automática a su propia sabiduría y a la lógica del reinado que él ha establecido. Un Dios impotente frente a las demandas cotidianas de su creatura, pues su lógica no pertenece al mundo de lo contingente, sino de lo trascendente. Por su parte, en el mundo humano, cambiante e imprevisible todo es gestionable desde el entendimiento entre humanos, por eso en él cabe, realmente, la posibilidad del gobierno. A través de un recorrido entre textos del cristianismo primitivo y medievales, Agamben argumenta que el gobierno moderno se hace presente para administrar el espacio intermedio entre los acontecimientos particulares e imprevisibles de los hombres y la providencia general o poder absoluto de Dios. Las decisiones de los hombres que gobiernan ese terreno tenderán a aplicar la providencia general a las situaciones particulares que viven, haciendo un cálculo, al final de cuentas una interpretación, de los efectos que tendrían sus decisiones respecto al desconocido plan de salvación. En palabras de Agamben, los primeros gobernantes de la oikonomía moderna "asumirían una idea de orden fundada en el juego contingente de los efectos inmanentes" ${ }^{38}$.

Esta distinción entre el reino divino, inaccesible e incomprensible y el gobierno humano puede encontrar una aplicación en el caso de la crisis del coronavirus. La verdad sobre el origen y la solución última a la pandemia parece escapar de nuestro marco de pensamiento. Más allá de la esperanza de una vacuna, el conocimiento total sobre el fenómeno COVID 19 parece resguardarse en un lugar que nos es

\footnotetext{
${ }_{36}$ Agamben, G. El reino y la gloria, op. cit., p. 119.

37 Rodríguez, R. "Teología y política". Revista de libros, no 156, 2009, p.3.

38 Agamben, G. El reino y la gloria, op. cit., p. 138.
} 
ajeno y ante el cual sólo nos han quedado las interpretaciones e improvisaciones de la gestión humana. Por eso, aquella crítica que Jean-Luc Nancy realiza a Agamben, en la que le replica que la experiencia que estamos viviendo es una "excepción viral y no una excepción político-jurídica" ${ }^{39}$ refleja la dualidad entre la gestión terrenal y el misterioso núcleo de poder que Agamben describe en el Reino y la Gloria. En la distinción realizada por Nancy para cuestionar a Agamben, se instala una aplicación actual de la diferencia entre reino y gobierno, pues refleja nuestra incapacidad natural para acceder al origen del problema, de tal manera que nos procuramos, sobre lo desconocido, estratagemas y eufemismos como el de la "excepción viral", tras los cuales escondemos nuestra propia impotencia ante un problema que nos rebasa en entendimiento y control. Ciertamente, no es muy claro a qué se refiere Nancy con una "excepción viral" y en qué se diferencia de una excepción político-jurídica. Lo que sí es claro es que, dado que no somos, como humanidad, capaces de acceder a un poder trascendente para afrontar el problema del COVID-19 desde su conocimiento pleno, la respuesta que se ha generado a la crisis a través de cuarentenas, imposiciones de autoridad y restricciones a las libertades, son las mismas medidas del mundo terrenal e imperfecto del gobierno que hemos construido y empleado siempre. A esa misma gestión económica de la vida pertenecen, de hecho, categorías como la de Nancy, relativa a una supuesta "excepción viral", pues con ellas se intenta proveer de una misteriosa legitimidad a las viejas y útiles mordazas político-jurídicas de Occidente. En síntesis, el estado de excepción en el que vivimos se ha basado en una gestión orientada a cálculos e interpretaciones sobre un poder trascendente que nos es inaccesible, luego, los juegos contingentes de efectos inmanentes que creamos alrededor de las emergencias como el COVID 19 , y no sólo en ella, ${ }^{40}$ merecen, como creación humana, ser sometidos a un cuestionamiento constante.

\section{¿Mercaderes de la muerte?: La respuesta glorificadora de Žižek}

LA GENEALOGía AGAMBENIANA toma un giro inesperado y provocador cuando, en la segunda parte del El Reino y la Gloria, el filósofo italiano se pregunta por el círculo burocrático más cercano al poder de Dios; los ángeles. Se pregunta: ¿qué sucede

\footnotetext{
${ }^{39}$ Nancy, J.-L. “Excepción viral” Sopa de Wuhan, Argentina, ASPO, 2020, p. 30.

${ }^{40}$ En la historia de Occidente, la misma lógica se ha empleado para construir respuestas legítimas, dotadas de misterio, por ejemplo, frente a la amenaza del terrorismo; la misma estratagema del "aura sagrada" ha rodeado la justificación de las "guerras prodemocráticas" y la "guerra justa”. Todas estas experiencias, no obstante, pueden reducirse al uso de una gestión política de la muerte de unos individuos, para beneficio de otros: sobre esa "continuidad entre casos", Agamben encumbra su concepto de biopolítica y de estado de excepción permanente.
} 
con ellos y su especialización funcional cuando el día del juicio final llega? La pregunta la realiza a la tradición teológica, pero la respuesta la halla en la ontología heideggeriana: según Agamben los ángeles que, en principio, no cumplirían más funciones que satisfacer las demandas de la humanidad, se quedarían limitados a realizar su función más esencial, aquella es: glorificar a Dios, manteniéndolo aislado por la propia gloria. Vaya paradoja la que descubre Agamben; ni un hipotético día del juicio rompería la lógica de la bipolaridad de la máquina de gobierno revelando el poder absoluto de Dios. Esta paradoja, como podemos intuir, tiene implicaciones en la actual crisis del coronavirus y en las propuestas de un mundo alterno por construir que encontramos, por ejemplo, en filósofos como Slavoj Žižek, para quien esta crisis es la oportunidad idónea para que la humanidad realice el verdadero ideal comunista.

Antes de analizar la postura de Žižek volvamos a Agamben. Ante un hipotético fin del mundo, el lugar del poder absoluto continuaría aislado por su propio esplendor y por la aclamación que se realiza sobre él. Desde el punto de vista humano, esto develaría que el poder puro es, en esencia un lugar vacío, una nada que, para ser poder; necesita de la glorificación de los ángeles en el fin del mundo o antes que ello ocurra; de los hombres como sus administradores terrenales. La gloria es para Agamben, en consecuencia, la esencia o el concepto de lo político; afecta al poder supremo de Dios de una forma distinta a lo que puede hacer sobre los hombres, pues encierra una correlación: por un lado, Dios depende de la gloria y la gloria de Dios y, por otro lado, de la glorificación deviene la gloria; pues no hay gloria sin glorificación. Es decir, lo único cierto, en consecuencia, es que el poder reside en quienes son capaces de glorificar al núcleo sagrado. Allí se encuentra el poder humano, que basándose en creer que hay un poder divino, gobierna conforme a esa creencia. En otras palabras, Agamben identifica que el poder de la máquina gubernamental de Occidente, aquel que ha devenido en el actual dominio absoluto sobre la vida social e individual, se sustenta en la ovación y la aclamación constante de los mismos hombres para existir. En resumen, en sí, el poder más puro, esencial, es un núcleo vacío rodeado por el velo de la gloria, ese velo, por un lado, lo glorifica, es decir; lo eleva al lugar de un poder absoluto y, por otro lado, lo esconde de la humanidad bajo un velo de misterio. Esta metáfora teológica es trasladada por Agamben al plano del individuo. El hombre sin política es como ese Dios en esencia inocuo y aislado, descrito por Agamben como un ser en reposo, inmóvil y ajeno a las tareas de gobierno, su vida adquiere un sentido cuando es rodeado por la Gloria; al tiempo que la misma se convierte en su condena: lo conduce a perseguir, a través de la política, utopías que, en cuanto tal son inaccesibles; son promesas sobre un reino que, escritas a golpes de glorificación, marcan con su sello indeleble nuestras identidades políticas. 
Para Agamben, la inacción de la gloria reúne aquello que llamamos política: rodea la simpleza de la especie humana, su condición natural de carencia de identidad se supera gracias a ella, la política entendida como Gloria, nos provee de un propósito que, aunque esté desprovisto de pureza y justifique el control más absoluto sobre la vida, es al final nuestro propósito. Podría decirse que teología y política viven en la antesala a un trono vacío; construir esa antesala llena de mecanismos de gobierno y, simultáneamente, glorificar lo sagrado inaccesible; es el propósito de la política moderna.

En conclusión, la Gloria como inacción une lo sagrado y lo profano, da lugar a lo político como un sentido impuesto a la vida biológica. En la actualidad de la cultura occidental, el poder hegemónico de la Gloria resulta problemático y se expresa, por ejemplo, en lo que conocemos bajo el nombre de "opinión pública", la cual, como sabemos es construida por los medios de comunicación, las redes sociales y, en general, por las mass media. La fuerza de esta opinión pública oculta un centro vacío de verdad que, no obstante su vacuidad, gobierna sobre las posturas disidentes: no posee verdades puras $\mathrm{y}$, sin embargo, su inercia afecta a todas las posiciones políticas, inclusive las mejor sustentadas, de manera que siempre tienden a ajustarse a ella como paradigma de lo "políticamente correcto". Del mismo modo opera la "razón de las mayorías" en la democracia y el posicionamiento de algunas causas en la esfera pública que, no por ser más difundidas o generar más "ruido", son más apremiantes y merecedoras de justicia.

Agamben cuestiona, entonces, las pretensiones "pseudocientíficas" de los enfoques que intentan poner nombre, dotar de una explicación y divinizar a la Gloria. Por un lado, cuestiona a Habermas quien propone cierta idolatría a la búsqueda del consenso como una "utopía alcanzada" de canalización institucional de la soberanía y los conflictos que ésta genera ${ }^{41}$. Para en Habermas, la esfera pública y la deliberación remiten al polo del gobierno, pero para Agamben ésta es solo una de las formas modernas que adquiere la vieja aclamación glorificadora de la oikonomía moderna. Por otra parte, cuestiona el poder de la decisión legitimada por un "pueblo aclamador" que Schmitt exalta como soberana en Teoría de la Constitución; ese es solo el otro polo de la glorificación, según Agamben ${ }^{42}$. Tanto Habermas como Schmitt, tratan de imponer un estatuto de lógica y divinidad a lo que, para Agamben, es una sustancia inaccesible. Deliberación y decisión, no son más que espectáculos litúrgicos, dos artefactos eufemísticos creados por el hombre para explicar lo que no tiene explicación; para ubicar en el lugar del "trono vacío" que describíamos antes, un rol

\footnotetext{
${ }^{41}$ Agamben, G. El reino y la gloria, op. cit., p. 278.

42 Ibid., p. 187.
} 
de autoridad que no les pertenece y presentarles como los orígenes "descubiertos" del poder de los gobiernos. Lo cierto, según Agamben, es que el origen de una aceptación general a leyes que, por ejemplo, definen la vida o muerte de miles de personas es realmente desconocido; lo que hace que una ley así sea tomada como una obligación aceptada por parte de la ciudadanía no nace del debate o la deliberación previa o del simple hecho de decidir. La deliberación y la decisión son partes de una economía del poder, no constituyen el poder soberano trascendente, en cuanto no hay nada tan absolutamente racional e indiscutible en el interior de una decisión o una deliberación, que sea capaz de explicar la aceptación generalizada de órdenes que definan quiénes viven y quiénes no.

La propuesta de Slavoj Žižek respecto a un aflorar solidario y humanista del que resultaría un verdadero comunismo, no deja de llamar la atención, de alguna manera se ajustaría a una de las posibles respuestas que Agamben analiza en la hipotética situación del día del juicio final. Sobre esto habría que preguntar más a Žižek que a Agamben, si la propuesta de un "comunismo poscovid" 43 es o no otro acomodo de la oikonomía moderna para mantener la fractura originaria entre reino y gobierno, es decir, ¿no sería ese nuevo comunismo otra forma de glorificación? Cabe la posibilidad de encontrarnos frente a otro "espejismo de divinidad", otro performance terrenal como el de la deliberación habermarsiana y el decisionismo schmittiano, sin embargo, la imprecisión de detalles en la propuesta neocomunista que hace Žižek le exime de críticas en este punto.

\section{Conclusión}

Cuando Agamben indica que la respuesta de los Estados al COVID 19 es desproporcionada, lo hace sobre una base de conocimiento genealógico del gobierno, que le da la razón. Pues, desde esa perspectiva, las atribuciones autoritarias de los gobiernos son solo la radicalización más reciente de las formas de dominio absoluto sobre la vida social que han caracterizado a la cultura occidental desde sus orígenes.

Para Agamben, la biopolítica moderna se expresa en la crisis del COVID reforzando un estatuto de obligación del control sobre la vida humana que se sustenta en la indeterminación y la in-fundamentabilidad del poder. Esta indeterminación del "lugar" y fundamento del poder es más agresiva respecto al control que pueden ejercerse, por ejemplo, en formas concretas de gobierno como el "totalitarismo" o la "dictadura". El estado de excepción que experimentamos se presenta como un

43 Žižek, S. Pandemia, op. cit., pp. 101-111. 
"umbral de indeterminación entre la democracia y el absolutismo", tal como lo ha propuesto Agamben desde hace décadas ${ }^{44}$. Occidente, según Agamben, ha construido un estado de excepción que "no es una dictadura, sino un espacio vacío de derecho, un vacuum jurídico, es decir, una zona de anomia en la cual todas las determinaciones jurídicas son desactivadas ${ }^{45}$, como respuesta a una perversa e íntima solidaridad entre democracia y totalitarismo ${ }^{46}$. El estado de excepción generado por el COVID 19 es solo la continuidad de ese orden.

Agamben se ha equivocado en un punto: el COVID 19 no es una gripe normal, ha sido la más importante de todas las gripes que ha podido atestiguar desde que inició su programa de investigación en $1996^{47}$ pues, para bien o para mal, ha permitido materializar el sentido de su extensa y abstracta obra sobre el estado de excepción permanente ante sus críticos. Tal vez la cruda realidad que nos obliga a experimentar hoy las decisiones biopolíticas de primera mano; nos permita comprender por qué el mundo, según Agamben, se ha transformado en un "lugar en que el estado de excepción coincide perfectamente con la regla y en que la situación extrema se convierte en el paradigma mismo de lo cotidiano" ${ }^{48}$, es decir, por qué el mundo se ha transformado en un gigantesco campo de concentración.

\footnotetext{
${ }^{44}$ Agamben, G. Profanaciones, op. cit., p. 26.

45 Ibid., p. 98.

46 Ibid., p. 154

47 Agamben, G. La comunidad que viene, Valencia, Pre-Textos, 1996, p. 51. Tomamos como referencia esta la publicación de La comunidad que viene, por ser la primera vez que menciona la figura del homo sacer.

48 Agamben, G. Lo que queda de Auschwitz... op. cit, p.50.
} 


\section{REFERENCIAS BIBLIOGRÁFICAS}

Agamben, "Contagio", Sopa de Wuhan, Argentina, ASPO, 2020.

Agamben, G. ¿En qué punto estamos? La epidemia como politica (T. D’Meza \& R. Molina-Zavalía, Trads.). Buenos Aires, Adriana Hidalgo, 2020.

Agamben, G. "Aclaraciones". La fiebre. Pensamiento contemporáneo en tiempos de pandemias. Argentina, ASPO, 2020.

Agamben, G. "La invención de una epidemia", Sopa de Wuhan, Argentina, ASPO, 2020.

Agamben, G. "Reflexiones sobre la peste" Sopa de Wuhan, Argentina, ASPO, 2020.

Agamben, G. El reino y la gloria. Traducción: Flavia Costa y Edgardo Castro, Buenos Aires, Editorial Adriana Hidalgo, 2008.

Agamben, G. Estado de excepción. Homo Sacer II, 1, Buenos Aires, Adriana Hidalgo, 2004.

Agamben, G. Homo sacer. I. El poder soberano y la nuda vida, Valencia, Pre-Textos, 1998 .

Agamben, G. La comunidad que viene, Valencia, Pre-Textos, 1996.

Agamben, G. Lo que queda de Auschwitz. El archivo y el testigo. Homo sacer III, Valencia, Pre-Textos, 2000.

Agamben, G. Medios sin fin. Notas sobre la politica, Valencia, Pre-Textos, 2001.

Duque Silva, G. A. "El Carl Schmitt de los tanato-políticos: la veta de filosofía schmittiana en el pensamiento de Giorgio Agamben”. Praxis filosófica, (45), 2017.

Duque Silva, G. A., \& Del Prado, C. "A 100 años de la Constitución de Weimar ¿qué nos queda?: La herencia polémica de Carl Schmitt". Bajo Palabra. Revista de Filosofía. II Época, Madrid, 2020.

Esposito, R. "Curati a oltranza”. Antinomie, 2020.

Flores D'Arcais, P. "Filosofia e virus: Le farneticazioni di Giorgio Agamben", MicroMega, 2020, Disponible en: http://temi.repubblica.it/micromega-online/ filosofia-e-virus-le-farneticazioni-di-giorgio-agamben/ 
Foucault, M. "Il faut défendre la société", Cours au Collège de France (19751976), Paris, Gallimard-Seuil. 1997.

Galindo Hervás, A. "La gloria y el concepto de lo político en Giorgio Agamben", Revista de Estudios Sociales, (35),66-77, Colombia, Universidad de Los Andes, 2010.

Múnera, L., \& Benavides, F. Normalidad y excepcionalidad en la politica (Schmitt, Agamben, Žižek y Virno), Colección Gerardo Molina, (Vol. 13), Bogotá, Universidad Nacional de Colombia, 2008.

Nancy, J.-L. "Excepción viral” Sopa de Wuhan, Argentina, ASPO, 2020.

Rodríguez, R. “Teología y política”. Revista de libros, no 156, 2009.

Schmitt, C. Teología politica, Madrid, Trotta, 2009.

Žižek, S. Pandemia. La COVID-19 estremece al mundo, Barcelona, Anagrama, 2020.

DOI: https://doi.org/10.15366/bp2021.27.005

Bajo Palabra. II Época. No 27. Pgs: 105-124 